This is a pre-print version

The final version of the article is published in:

Development in Practice, 2013, Vol. 23, No. 4, 435-447,

http://dx.doi.org/10.1080/09614524.2013.790940

\title{
Reflexive engagements: the international development blogging evolution and its challenges
}

Tobias Denskus and Andrea S. Papan

\begin{abstract}
Writing weblogs (blogs) has become a substantial part of how development is discussed on the Internet. Based on experiences as blogger, this article is an exploratory case study to approach the impact of blogging on reflective writing, work practices as well as knowledge management. Based on research with development bloggers and the authors' own social media practice, the article undertakes an analysis of bloggers' motivations and the potential as well as limitations of blogs for different sectors of the industry, for example in academia, inside aid organisations and in understanding expatriate aid workers. Finally, the article explores the question of whose voice is represented in blogs.
\end{abstract}

\section{Introduction}

Writing, reading, and commenting on weblogs (blogs) is a substantial part of how international development is discussed on the Internet. Engaging with bloggers and their blogs offers insights into the evolution of how writing development takes place outside established academic discourses or official communication materials. Blogging has quickly become a method of writing that is gaining momentum but has not yet be analysed in more depth academically. This article is an exploratory case study to highlight the impact of blogging on personal reflective writing and work practices and broader questions of knowledge management or influencing development policy. The article starts with some methodological reflections and broad definitions of different types of blogs. Based on ten interviews with and written replies by popular development bloggers (five women and five men), we undertake an analysis of their motivations for writing and their experiences before we outline the potential as well as limitations of blogs for different sectors of the development industry. Finally, the article explores the questions of how personal writing projects can influence the politics of organisations, who participates and is represented in blogs, and how global an endeavour blogging has become.

\section{What does a development blog look like?}

Our engagement of approaches used by bloggers to reflect on development practice is guided by Driscoll and Gregg's $(2010,19)$ understanding of “sympathetic online cultural studies”, a research approach to online culture that can "appreciate the different rules and behaviours it 
This is a pre-print version

The final version of the article is published in:

Development in Practice, 2013, Vol. 23, No. 4, 435-447,

http://dx.doi.org/10.1080/09614524.2013.790940

exhibits and values”. Using a snowball sampling technique, we identified 20 bloggers and received written feedback from seven; additionally, three longer interviews were conducted by Skype. Important to this analysis is Browne's identification of being "embedded in the social networks” $(2005,50)$. Our use of a snowball sampling technique is intrinsically linked to having one's own development blog (http://www.aidnography.de) and being active on social media, and allowed for potential interviewees to check out the author's blog. The limitations of snowballing that Browne identifies also apply to this research:

"Social networks, as channels for recruitment, can be an advantage in some respects (for example, including those often ignored in studies that rely on random or representative sampling) yet a disadvantage in others (for example, excluding those not within friendship groups). Consequently, future studies which employ snowball sampling should be aware of the exclusions of the method and the potential of the personal involvement of the researcher's own social networks.” (Browne 2005, 57)

The final section of this article will elaborate further on the limitations of the "blogosphere" as a representative global forum for first-hand insights and local feedback on development realities. As recent quantitative research on the impact of economics blogs (McKenzie and Özler 2011) and the analysis of the readership of major development blogs (Algoso 2011) revealed, the blogosphere is dominated by Northern ideas and readers.

In addition, the Pew Internet Project indicates that, with the exception of LinkedIn, women are the majority of Internet users of all other social networking sites (i.e. Twitter and Facebook) (Brenner 2012). However, a comparable level of participation as producers of development blogs is not evident. The responses to Oxfam blogger Duncan Green's post “Is blogging (or commenting on blogs) a guy thing? And if so, why?” (Green 2012) not only suggested many female development bloggers may be less visible, but also invoked a broader critique about gendered perceptions of critical writing (Denskus 2012). Because we are looking at blogging in a global context, questions about political, economic, social, and cultural constructs that may hinder women's engagement in blogging must be considered. So too, however, as in traditional gender and development literature, questions around the nonhomogenous representation of women's experiences whether from or temporarily based in the Global South are equally relevant in the virtual world and require further, in depth examination (Somolu 2007). It is beyond the scope of this paper to examine the gender dimensions of development blogging as relating to gender and development (GAD) theory 
This is a pre-print version

The final version of the article is published in:

Development in Practice, 2013, Vol. 23, No. 4, 435-447, http://dx.doi.org/10.1080/09614524.2013.790940

and practice, and in addition to issues of representation, more research on to what extent blogs can strengthen gender equality by breaking down traditional barriers to women's engagement and displace patriarchal strongholds in public debate and dialogue (Eltahawy 2011) are needed. This article aims to be a starting point to discuss blogs and blogging in international development and offers suggestions for future research.

As difficult as it is to define a so-called typical blog, we will introduce six, sometimes overlapping, categories that are evident from research and blogging. The blogs are all products from different types of engagement with international development. As such, these blogs identify a range of genres from commentary on international politics to personal reflections and criticism about the development industry.

1. Blogs written by individuals. These individuals have no organisational affiliation, but are written by bloggers with substantial practical experience in the field. They use blogs to promote their advisory services or for general reflections to engage with a broader public on contemporary topics in development, e.g., donations after the Tsunami in Japan, or inkind donations to Africa (Schimmelpfennig 2011).

2. Blogs written by individuals with an organisational affiliation. This is the largest category and is often associated with the United Nations system, international non-governmental organisations, or local development projects. With few exceptions, bloggers stress that the views expressed in the blog are their own and not of the employer.

3. Blogs written by academics. There is a range of popular blogs written by academics based, in our research, at North American universities.

4. Blogs written by aid workers in the field. These are also mostly anonymously written by mainly expatriate aid workers.

5. Official blogs written by staff of Think Tanks and other policy institutions. These blogs are usually hosted on the organisation's website, but may not always reflect official policy.

6. Blogs written by development students, interns, or non-professionals in training, usually in a developing country context. These blogs are maintained to journal about personal experiences and to engage family and friends in the development processes; they can are also 
This is a pre-print version

The final version of the article is published in:

Development in Practice, 2013, Vol. 23, No. 4, 435-447,

http://dx.doi.org/10.1080/09614524.2013.790940

used to fulfil internship requirements for public information sharing.

The transnational and multi-sited nature of development has resulted in many hybrids, e.g. a blogging graduate student who splits her time between her field site in Africa and her academic home-base in Canada, writing her personal blog as well as contributing to a news website or blog of an organisation from which she received a scholarship.

\section{Why do people blog about development?}

The research found that development bloggers write and share purposefully and with the aim of having a dialogue with their readers. We argue that active engagement with social media has become an important feature for communication and feedback on development issues and practices, as highlighted by the comments of the interviewees. The anonymous blogger talesfromthehood writes:

"Because I blog about the issues that I'm thinking about and dealing with in the course of my everyday job, I'm able to gain a wide spectrum of input and perspective on those issues, whether via comments on my posts, posts on other blogs that 'riff' off of mine, or - again twitter conversations spun off of those same blog posts...I spend more time on aid-related blogs and twitter than I spend keeping up with technical things. It’s that important.”

Linking insights through blogging to practical work and organisational debates is another key feature as one blogger explains in an interview:

"Blogging allows me to think through ideas and concerns that I have (I think better through translating my thoughts into writing) and I can put them out to the blogosphere to see if I'm on the right track or not. I can vet ideas and hear criticisms of them before I venture into trying them out. In terms of big aid policies and decisions, reading a variety of viewpoints helps me define what I think about things. Sometimes I don't have access to these types of policy discussions within my own organisation, either because they are happening in meetings I'm not participating in or at levels that I'm not able to access. Being active in reading and writing blogs means that you can be having these discussions in real time with other professionals in your field. In terms of their impact on learning and positive change, many of the ideas that I have brought into my organisation have been born from reading blogs or discussing other people’s blogs.” (Blogger 1)

Another blogger talked about her engagement in a very similar way:

“Blogs can help to focus an individual's own thinking about his/her work, providing an additional tool for reflective practice. In addition to the individual focus, publishing this thinking on a blog makes one's thinking easier to share and can lend itself to creating a small 'community of practice' if others comment on the author's posts... . When I think about 
This is a pre-print version

The final version of the article is published in:

Development in Practice, 2013, Vol. 23, No. 4, 435-447, http://dx.doi.org/10.1080/09614524.2013.790940

creating a blog post, I do spend more time analysing actions and activities in a more timely manner than I might have done without the incentive of composing a blog. Comments made on my blog have often provided me with additional ideas or information that I might not have had otherwise that I can apply to my work, and I believe my blog serves that same purpose for my readers.” (Blogger 2)

In these excerpts, a learning process becomes visible and transparent that is often hidden from the view of development research, policy, and practice. This iterative process moves from thinking to writing a blog post, posting the post, having discussions, and getting feedback on the post. This shows how blogging can help to open up a liminal learning space, "a space in which someone is being transformed, acquires new knowledge or acquires new status and identity within the community” (Eckerdal et al. 2007, 2). As one blogger who is currently based in a fragile post-conflict context affirms:

"So much information about development work that appears in blogs and in newspapers and on NGO websites is disingenuous, dramatised, and polarised (good versus evil, right versus wrong, rich versus poor, clean versus dirty) which is (a) not honest, and (b) detrimental... [I use blogging] [m]ainly just [for] networking. I've made friends through it, met interesting people, had great conversations. It also forces me to think through the language that I use (I write a lot for my job) and the own thoughts that I have about the work I'm doing." (Blogger 4)

Blogging about development has the potential to become part of reflective writing practices to engage with a potentially global readership which can add transparency and accountability to everyday, small-scale development processes often hidden from traditional publications.

Another feature that is noted frequently is that blogging about development often does not remain a virtual process, but leads to real-life encounters and new professional opportunities. As Blogger 1 describes:

"[Blogging] has helped in developing numerous working partnerships and with networking. People can see what you are about, they can see what you think, what your personality is and what your underlying working principles are, and if you know your stuff or not. Blogging is about 100 times better than reading a CV. Tweeting and blogging have led to numerous offline meet-ups as well, and there is where partnerships, joint work and learning/sharing continue to grow. Blogging has helped me and the organisation where I work to make a name in my area of expertise."

Another blogger at an earlier stage of his career remarked how being active has helped in his personal networking and taking advantage of unique professional opportunities: 
This is a pre-print version

The final version of the article is published in:

Development in Practice, 2013, Vol. 23, No. 4, 435-447, http://dx.doi.org/10.1080/09614524.2013.790940

"Professionally, my blog has allowed me to be on the Huffington Post, attend UN Week, meet aid workers, build connections, and likely land a new job. It has been a fantastic networking tool for someone who is as young as myself and is looking for ways to responsibly take part in this work. In addition, I can learn from those who have years of experience to know what fields provide the most opportunity and how to further my involvement in such fields.” (Blogger 3)

The possibilities of personal learning and discussions also offers entry points for those who work outside the industry's mainstream and provides opportunities for non-formalised learning. A British blogger uses his writing for reflection, but also to promote his alternative views on a particular health-related topic:

"As for my research, my blog is my research. I have contacted a few academics about doing further research and have got nowhere. I don't have the money to pay to do more study and I don't think doing an MA should cost anywhere near as much as it does considering what the institution does for its fees. So writing blogs and emailing people and commenting on their blogs may, in the end, be the sum of what is a lot of reading, writing, discussing and thinking." (Blogger 5).

Another alternative use was outlined by a southern African blogger we reviewed in this research. She appeared to be a less active blogger, judging from the quantity of her posts, but she made a very clear statement about why she writes and uses the blog:

"So I write to protest. I write to disagree. I write to simply state that I think otherwise. I write to flip to the other side of the coin. In my writing I identify myself as a feminist. I do not make apologies for it. Because feminism as an ideological position reaffirming what I identify with - the pursuit for social justice for women in a world where patriarchy legitimizes the conditions of our subjugation.” (Ndou 2010)

These three broad motivations to maintain a blog - writing for personal and professional learning, writing for networking, and writing to express alternative ideas and advocacy - may not seem surprising and they apply to other social media as well. However, they are an indication that reflective writing to engage with a potentially global audience has become a regular activity for a growing number of professionals who work in the field of development. AidSource, “The Humanitarian Social Network” was launched in 2012 and has hundreds of members who actively engage in virtual discussions that engage with a broad range of development issues.

Official blogs tend to maintain a coherent narrative of policy, best practice, and positive 
This is a pre-print version

The final version of the article is published in:

Development in Practice, 2013, Vol. 23, No. 4, 435-447, http://dx.doi.org/10.1080/09614524.2013.790940

news, and rarely admit complex challenges, let alone failures. The final section will draw on the statements from the interviews and literature and will give a tentative answer to the question of how blogs can challenge development thinking and be used strategically to open spaces for organisational learning processes. The following section will analyse three different organisational contexts to explore how blogging is changing interactions and discussions.

\section{The potential of development blogging in different organisational contexts}

Clearly, blogs have become a public resource for sharing and debating development. In this section we identify three areas where blogs have the potential to supplement, challenge, and even change traditional perceptions and practices, e.g. in academia, inside aid organisations, and with regard to understanding expatriate aid workers and their work on the ground. Although academic research and publications contribute to a better understanding of development work- and lifestyles (e.g., Fechter and Hindman 2011; Mosse 2011), the increasing number of students who engage with development studies refer to blogs as resources for first-hand experiences and dilemmas that come with working in the development sector. The author's own blog describes the challenges of doing a $\mathrm{PhD}$ in development studies (Denskus 2011a) or on the complexities and positionalities of working in the "development industry" (Denskus 2011b). These posts have generated hundreds of page views, many comments, and direct feedback via email - something traditional publications often do not achieve. But emilyrtanner, a commentator on the popular blog talesfromthehood, makes another important point when commenting on the post Aid Blogging matters (?):

"As a student, I find aid blogs instructive as they shed light on some aspects of aid that you do not get in a classroom...Graduate school can provide a platform for debating theories. It can also provide useful skills (learning about how to do a log-frame and evaluations and designing good indicators). But it ignores a lot of issues in foreign aid. I personally think all students should have a blogroll of good aid blogs to keep up to date on the debates and issues of the day, as well as gain insight into the actual types of jobs they will be doing. Aid bloggers are like a collection of mentors. You're giving us the dirt of what it's really like. Instead of having to discover for ourselves many of these lessons, you are teaching the next generation of aid workers what's been tried and what's failed and what they're going to be up against.” (talesfromethehood 2011) 
This is a pre-print version

The final version of the article is published in:

Development in Practice, 2013, Vol. 23, No. 4, 435-447,

http://dx.doi.org/10.1080/09614524.2013.790940

At the moment, however, it can be difficult to combine blogging with other academic activities, which in turn make it difficult for researchers to share knowledge and be acknowledged in the academy with regard to hiring or promotion through their blogs. As Bill Easterly and Laura Freschi from New York University write in their closing note of the popular development blog Aid Watch:

"The simple reason for ending the blog is that we want to free up our own time for writing longer and more substantive pieces, both academic and non-academic, on development. The blog is a hungry mouth that always wants to be fed, and the longer projects we'd like to take on don't fit in with those constraints.” (Freschi 2011)

It is too early to make more general claims as to how development blogging has an impact on academia, but for students and for teaching purposes they are an appreciated resource and have become part of development studies curricula. One of the interviewed bloggers made an interesting link between her learning and the discussions she has in the virtual world:

"A lot of students read my blog also, and I hope that it will have an impact on their learning process as well (and I also read a lot of students' blogs). In some ways, I see Twitter discussions and blog reading/discussion as the equivalent of an online Master's Degree, because I am constantly reading, discussing, researching, and writing with others, however it's possibly even better because I interact with people outside my field, with varying viewpoints and backgrounds, and with people who are much less or much more advanced than I am, so I can learn from experiences, hear 'innocent' questions that make me really think, bring in innovations, and listen to those with years of experience, all at the same time, so it reduces the silo effect or the preaching to the choir issue.” (Blogger 1)

Comments like this highlight a potential opportunity for academic programmes to combine traditional teaching methods and assessments with the demand for online education where blog reading, writing, and commenting is linked to theories and academic literature and debates. This being said, there are important questions about the anecdotal nature of blogging and the rigour of blog content. Framing development practice through discourse and theory analysis is an important element to strengthening the growing academic discipline of development studies. Traditional academic skills will need to adapt as researchers and teachers become navigators of the growing blogosphere, which requires time to identify relevant blogs and keep tuned in real-time to these developments. Development blogging is rooted in the present and the local, attributes which are prized in development practice. Yet they are also inherently subjective comments and reflections and as such are can be 
This is a pre-print version

The final version of the article is published in:

Development in Practice, 2013, Vol. 23, No. 4, 435-447, http://dx.doi.org/10.1080/09614524.2013.790940

significantly limited in scope and depth of the complexities of underlying social, cultural, and economic processes or historical perspectives. Academic libraries will not become outdated soon, but development studies programmes need to take virtual learning aspects more seriously and complimentary to traditional teaching and learning approaches.

\section{Large aid organisations}

As already indicated, the knowledge gained from the blogging process often feeds back into individual work practices. Even if most development bloggers blog in their private capacity and often anonymously, they clearly see an added value for their professional practice:

"I think that the blogosphere is often way ahead of organisations themselves, and that the discussions that are happening in the blogosphere will be those that development organisations are tackling next year.” (Blogger 1)

In an interview with another development blogger, the anonymous roving bandit explains how blogging is going to change organisational cultures, but that at the moment official party lines prevent fully open exchanges in the virtual world:

"One day, aid agencies will brag about the bloggers they have on staff. This will happen when they realize the best aid agencies are platforms for conversations and learning rather than infallible oracles of aid wisdom. Until then, many bloggers will have to remain anonymous...I can tell you that I have a large and growing following within my employing organisation. Some of those people know who I am, but many do not. To a large extent I'm saying things on Tales From the Hood [another blog] that we all talk about at Starbucks (during lunch break, of course) or during happy hours. And so in that sense I don't think I'd have much to fear from my professional colleagues. My fear in 'coming out' would be more around the organisational culture, which (like every NGO that I'm specifically aware of) has a very low level of tolerance for opinions not strictly in alignment with the 'party line'." (Whittle 2010)

Many organisations have started to use blogs and social media to communicate with stakeholders, but often in more traditional ways, i.e. to share reports, success stories, or funding appeals. Waters et al. (2009) analysed 275 Facebook profiles of non-profit organisations alone, and other organisations have also taken about a variety of social media activities, including blogging. Ian Thorpe, who works in the United Nations (UN) system, uses his blog to write about knowledge management and how his work is influenced by social media. He has taken the idea of communities of practice that the UN has implemented 
This is a pre-print version

The final version of the article is published in:

Development in Practice, 2013, Vol. 23, No. 4, 435-447,

http://dx.doi.org/10.1080/09614524.2013.790940

internally to some extent to a global public audience, but this is a rare example. As one anonymous blogger remarked in an interview, a big question remains whether those in managerial and powerful positions have started to engage with blogs and what difference it makes in their decision-making processes:

"I think there's tremendous potential for positive change. I see that potential coming in two specific forms. First the Internet sort of become[s] a global water-cooler or coffee room or pub, where people can and do say the things that, for a wide variety of reasons - seem to never be said in aid organisations' headquarter conference rooms. So in that sense, there's definitely a degree of honesty and introspection about aid work that for the first time is more or less open to the wider audience. The question remains, though - do those with the power to make the needed changes read those introspective, honest blogs? And if so, do they act on what they read? Your guess is as good as mine.” (Blogger 4)

A recent research project that analysed 34 blogs and more than 3,000 Twitter updates during the Millennium Development Goal summit in New York in September 2010 found practically no evidence that social media were used for critical feedback and engagement and that the global summit rituals remained unaffected by global virtual civil society (Denskus and Esser 2013). It still seems to be a long way before the positive change that blogging documents and facilitates trickles up into conference rooms.

\section{(Expatriate) aid workers}

Many of the content providers that were mentioned as resources for students and researchers are expatriate aid workers working and living abroad. Many mention the idea of writing a blog as a mixture of a global sounding board for ideas and practical challenges, to organise their thoughts in writing, and to access the "global water cooler" discussions that may be difficult to access in remote field locations where the Internet remains an important personal and professional life line. Blogging becomes a reflection of the often blurred boundaries between work and private lives that aid workers experience in developing countries. But in addition to the personal reasons and implications for reflective practice, new and innovative ideas are tried out through blogs. One example is the use of blog post and feedback on strategy development that Engineers Without Borders Canada in Ghana used to make its strategy-building process open and transparent: 
This is a pre-print version

The final version of the article is published in:

Development in Practice, 2013, Vol. 23, No. 4, 435-447,

http://dx.doi.org/10.1080/09614524.2013.790940

“This is an experiment! The plan is to outline our team's strategy development process and the various investment opportunities we have, then seek external feedback on where we can invest and how we can play a bigger role in the agric sector.” (Antcliffe 2011)

To elaborate on the dilemma of having to make funding decisions based on limited information, Jennifer Lentfer used her blog to ask the readers for feedback and comments:

"Would YOU fund this organisation? In determining whether to give [a Zimbabwean organisation working on HIV/AIDS] a second small grant, aside from the original proposal and financial report, this was all I had to go on. They had not received a site visit from our organisation and one was not soon anticipated.” (Lentfer 2011)

These are just two interesting examples that highlight how blog writing, engagement with a global audience, and insights into daily work realities of organisations can come together and create discussions outside established communication challenges.

Questions about the scale of such exercises or lack of rigorous evaluations about the usefulness have yet to be undertaken, but there is space for participatory engagement that once again requires good facilitation skills.

\section{How global is development blogging?}

As the previous sections have shown, there is not a single and simple narrative emerging with regard to who blogs and how it affects professional practice, organisations, and discourses in international development. But the large number of blogs that exist, the level and breadth of readership, and the variety of development volunteers, students, and professionals that may be directly or indirectly influenced by these blogs is significant. The desire to tell stories from an insider's perspective and outside the official organisational communication channels comes across as one important theme. To share knowledge as mentors as well as to access gleanings for educational purposes, in particular normally experiential, first-hand insights, is another theme. Virtual activities may not yet have the potential to influence macro development policy or global events as the research of the MDG summit shows, but reflective writing on development is a politicised effort. Bolton, calling reflective practice a "political and moral project”, outlines a different arena for political change that can start through personal reflections or reflective writing:

"The term reflective practice covers activities from deep life, work and organisation-changing critique to rote box-ticking practices seeking to make professionals accountable to and 
This is a pre-print version

The final version of the article is published in:

Development in Practice, 2013, Vol. 23, No. 4, 435-447, http://dx.doi.org/10.1080/09614524.2013.790940

controllable by increasingly bureaucratic and market-led organizations. The paradox is that reflective practice is required by the masters, by the system. Yet its nature is essentially politically and socially disruptive: it lays open to question anything taken for granted.” (Bolton 2006, 204)

Development blogging is the virtual extension of a long tradition of engaging with and critiquing development. However, it is more widely accessible than publications or conferences and offers critical writing right from the fingertips of the community. It is also generic and bottom-up-driven as individuals are always in charge of their writing (e.g., anonymously), regularly, embedded in larger networks for sharing (e.g., Twitter or Facebook). Development blogging can happen on the inside as bloggers write on organisational laptops and use the office infrastructure for their activities. Development blogging does not need a designated space, special training, workshops, or degrees, enabling dialogues between those with varying levels of development knowledge and experience, and working in different roles, for example volunteers, academics, and practitioners.

However, as the interviewed bloggers explained, at this point their writing has not been officially recognised by their organisations, even though its productive impact on their personal learning and knowledge management is acknowledged by most bloggers. Reflective practice and writing can influence formal supervision and organisational change processes (cf. Hay 2007) and many development organisations have not started to explore this potential. The remark of one interviewee that her organisation allows staff to suggest a tweet to the communication officer who selects one or two for publication at the end of each week shows that understanding social media is still at its infancy in many organisations. One key question is how the global water cooler that one blogger mentioned can be incorporated in organisational spaces. Rick Iedema et al.’s research on interactions on a hospital floor and the use of the "corridor bulge" as an informal space for communication outside strict hierarchies may be reminiscent of some the encounters in the virtual space:

"Commonly, clinical interaction is determined by quite strictly defined professional boundaries and rules and these are reinforced during ward rounds etc....Staff were enabled to step outside of their normal roles and busy work trajectories and engage with work issues in a way that only an interruption to behavioural flow makes possible... As a space whose social logic did not align with that of surrounding clinical spaces, the corridor bulge provided practitioners with reflective and creative or diffractive opportunities.” (Iedema et al. 2010, 44) 
This is a pre-print version

The final version of the article is published in:

Development in Practice, 2013, Vol. 23, No. 4, 435-447, http://dx.doi.org/10.1080/09614524.2013.790940

The question remains whether and how blogging can help shape new spaces in an organisation. This research suggests that it often appears to be a genuine, organic space and that organisations need to take it more seriously and think about social media outside the aim of reaching a bigger audience or sharing a report with a larger group.

One of the challenges in researching blogs and other social media is that although global in theory, the scope is very much limited to the Global North and some international hubs, e.g., capital cities in developing countries with reliable Internet access. Research for this article, but also research with a larger sample size of blogs and tweets for the MDG summit research found few contributions from local aid workers, researchers, and members of the public. Other challenges include the need to produce catchy, high-level writing in English that stands out as regularly interesting, relevant, and appealing so that readers return to your site. This raises interesting questions about critical voices in the virtual realm and how those affected by development projects can become part of the discussion and reflections process. These are questions that go beyond the scope of this research, but research on a community of information and communication technologies for development (ICT4D) bloggers (Hulsebosch 2011) indicates that even experts in a technical field find it difficult to overcome very practical challenges of ICT in developing countries. In the end, as interesting as the qualitative insights into aid worker's life- and work-styles are, and as useful as virtual activities are for organisational learning and change, the research suggests that development blogging often requires a relatively privileged position of being inside the development industry and that it often reflects a specific form of cosmopolitanism and multi-sited engagement with the world. In her book Going First Class, Amit identifies a fundamental reality of development practice when she writes that "many of the chapters in this volume are concerned with the tensions between different hierarchies and criteria of status and privilege as travellers move from one context to another” (2007, 2). Although many blog posts engage critically with the concept of the Western development discourse, their key motivations are to do a better job and to share their experiences so others do not have to repeat their mistakes.

\section{Conclusions}

Our research on development blogs has highlighted a range of interesting dynamics with regard to reflexive and reflective learning processes. Peer learning in the blogosphere, mentoring of students or colleagues through intergenerational exchanges between seasoned 
This is a pre-print version

The final version of the article is published in:

Development in Practice, 2013, Vol. 23, No. 4, 435-447, http://dx.doi.org/10.1080/09614524.2013.790940

veterans in the field and aspiring aid workers, and multidisciplinary inputs all contribute to learning processes.

One of the biggest challenges so far seems that while theoretically they are meant to be global in scope, blogs are predominantly used by a global elite of professionals engaged in development or students at universities. Issues around quality management, facilitation, and links to traditional learning spaces need more attention, too. Another big challenge is to link individual learning processes, reflective writing, and critical exchanges to broader organisational dynamics and development policy processes. As helpful and useful as blogging may be, the question how it ultimately can change the larger positivistic discourse of improving programmes - a discourse that may be hijacked by organisations as they start to think more strategically about their bloggers. Right now, as for example World Vision’s engagement with so-called “Mom bloggers” indicates (Shera 2009), short term marketing goals may be more important than longer term learning objectives. Is the reflective writing and practice through blogging powerful and politically charged enough to challenge the substantialist discourse dominating development organisations? Eyben refers to the relational concept of “messy partnerships” as an alternative vision of how aid organisations engage with staff:

"Messy partnerships is a relational approach that allows differently positioned actors to get a better grasp of systemic issues through mutual communication of their partial knowledge of the system. It implies providing neutral spaces where they can meet without any prior commitment, letting events develop at their own pace as an emergent process.” (Eyben 2010, 389)

Blogging and blogs may be useful in such processes, but at the end of the day Brigg's critical point about the limitations of reflective practices also apply to blogging:

"But his reflective task is not without dangers for there is an assumption, heavily relied upon and promoted by the self-help industry, that self-reflection and self-awareness are unequivocally valuable practices” (Brigg 2009, 1423).

Equally, development blogging needs to find a balance between potentially self-absorbed naval gazing of expatriate development workers and researchers, and meaningful engagement with local communities and their visions and communication needs. It needs to focus on 
This is a pre-print version

The final version of the article is published in:

Development in Practice, 2013, Vol. 23, No. 4, 435-447, http://dx.doi.org/10.1080/09614524.2013.790940

content as much as exploring a relatively new medium. At this point, it remains to be seen whether blogging can be more than a lifestyle tool that may improve individual practice, but fails to engage with broader, traditional structures - especially in the context of large aid organisations and communities in the Global South. There is little evidence that blogging and its learning processes influence macro policy-making. Organisational rituals and artefacts such as global summits, policy papers, and the powerful role of international organisations in research, policy, and practice still shape the discourse. Blogs can help to expose these rituals and continue to work towards an alternative virtual learning space that reflects new and diverse voices. These stories, admittances of failure, insights into complex local processes and realities of development as an industry and lifestyle can help introduce reflective writing to more people. Blogging remains a bottom-up process that has only begun to trickle up into classrooms, offices, meeting rooms, and village squares to change development policy and practice.

\section{Acknowledgements}

The authors would like to thank all the development bloggers who offered their insights, especially Thomas Murphy for comments on an earlier draft.

\section{References}

Algoso, D. 2011. "Blog survey findings.” Accessed October 3, 2012. http://findwhatworks.wordpress.com/blog-survey-findings/

Amit, V. 2007. Going first class? New approaches to privileged travel and movement. Oxford: Berghahn Books.

Antcliffe, E. 2011. "Strategy development in small-meal-sized chunks.” Accessed October 3, 2012. http://erinantcliffe.wordpress.com/2011/03/31/strategy-development-in-small-mealsized-chunks/

Bolton, G. 2006. "Narrative writing. Reflective enquiry into professional practice.” Educational Action Research 14 (2): 203-218.

Brenner, J. 2012. “Pew internet: Social networking (full detail).” Accessed October 3, 2012. http://pewinternet.org/Commentary/2012/March/Pew-Internet-Social-Networking-fulldetail.aspx

Brigg, M. 2009. “The developer’s self: A non-deterministic Foucauldian frame.” Third World Quarterly 30 (8): 1411-1426. 
This is a pre-print version

The final version of the article is published in:

Development in Practice, 2013, Vol. 23, No. 4, 435-447, http://dx.doi.org/10.1080/09614524.2013.790940

Browne, K. 2005. "Snowball sampling: Using social networks to research non-heterosexual women.” International Journal of Social Research Methodology 8 (1): 47-60.

Denskus, T. 2011a. "Should I consider a PhD in international development studies?” Accessed October 3, 2012. http://aidnography.blogspot.com/2011/01/should-i-consider-phdin-international.html

Denskus, T. 2011b. Who is the “development industry?” Accessed October 3, 2012. http://aidnography.blogspot.com/2011/06/who-is-development-industry.html

Denskus, T. 2012. “Is writing reflective blogs on development a girl's thing?” And if so, am I really a female blogger?” Accessed October 3, 2012.

http://aidnography.blogspot.ca/2012/03/is-writingreflective-blogs-on.html

Denskus, T., and D. Esser. 2013. "Social Media and Global Development Rituals: a content analysis of blogs and tweets on the 2010 MDG Summit.” Third World Quarterly 34 (3): 409424.

Driscoll, C., and M. Gregg. 2010. "My profile: The ethics of virtual ethnography.” Emotion, Space and Society 3 (1): 15-20.

Eckerdal, A., R. McCartney, J. E. Mostro“m, K. Sanders, L. Thomas, and C. Zander. 2007. From Limen to Lumen. Computing students in liminal spaces. Paper presented at the ICER 2007 conference, September 15-16, in Atlanta, USA.

Eltahawy, M. 2011. "Egypt's naked blogger is a bomb aimed at the patriarchs in our minds." Accessed October 3, 2012. http://www.guardian.co.uk/commentisfree/2011/nov/18/egyptnaked-bloggeraliaa-mahdy

Eyben, R. 2010. “Hiding relations: The irony of 'effective aid'.” European Journal of Development Research 22 (3): 382-397.

Fechter, A.-M., and H. Hindman. 2011. Inside the everyday lives of development workers: The challenges and futures of Aidland. Sterling, VA: Kumarian Press.

Freschi, L. 2011. “Aid Watch blog ends; New work on development begins.” Accessed October 3, 2012. http://aidwatchers.com/2011/05/aid-watch-blog-ends-new-work-ondevelopment-begins/

Green, D. 2012. “Is blogging (or commenting on blogs) a guy thing?” And if so, why? Accessed October 3, 2012. http://www.oxfamblogs.org/fp2p/?p=8943

Hay, J. 2007. Reflective practice and supervision for coaches. London: Open University Press. 
This is a pre-print version

The final version of the article is published in:

Development in Practice, 2013, Vol. 23, No. 4, 435-447, http://dx.doi.org/10.1080/09614524.2013.790940

Hulsebosch, J. 2011. “About blogging, tunnelling visions and knowledge entrepreneurship.” Accessed October 3, 2012. http://joitskehulsebosch.blogspot.com/2011/06/about-bloggingtunneling-visionsand.html.

Iedema, R., D. Long, and K. Carroll. 2010. “Corridor communication, spatial design and patient safety.” In Organizational spaces. Rematerializing the workaday world, edited by A. van Marrewijk and D. Yanow. Cheltenham: Edward Elgar, 41-57

Lentfer, J. 2011. "Would YOU fund the organization?” Accessed October 3, 2012. http://www.howmatters.org/2011/02/24/would-you-fund-this-organization/

McKenzie, D., and B. Özler. 2011. “The impact of economics blogs.” Accessed October 3, 2012. http://blogs.worldbank.org/impactevaluations/node/621

Mosse, D. 2011. Adventures in aidland: The anthropology of expert knowledge and professionals in international development. Oxford: Berghahn Books.

Ndou, D. 2010. “When I write - who can shut me up?” Accessed October 3, 2012. http://www.kubatanablogs.net/kubatana/?p=3620

Schimmelpfennig, S. 2011. "The dos and don'ts of disaster donations.” Accessed October 3, 2012. http://goodintents.org/disaster/the-dos-and-donts-of-disaster-donations-2

Shera. 2009. "Mom bloggers meetup with World Vision.” Accessed October 3, 2012. http://www.5minutesformom.com/6425/world-vision-meetup/

Somolu, O. 2007. “'Telling our own stories’: African women blogging for social change.” Gender \& Development 15 (3): 477-89.

Talesfromthehood. 2011. “Aid Blogging Matters (?)” Accessed October 3, 2012. http://talesfromethehood.com/2011/04/14/aid-blogging-matters/\#comments

Waters, R. D., E. Burnett, A. Lamm, and J. Lucas. 2009. "Engaging Stakeholders through Social Networking: How nonprofit organizations are using Facebook.” Public Relations Review 35 (2): 102-106.

Whittle, D. 2010. “Free the Aid Bloggers!” Accessed October 3, 2012. http://www.denniswhittle.com/2010/11/free-aid-bloggers.html 
This is a pre-print version

The final version of the article is published in:

Development in Practice, 2013, Vol. 23, No. 4, 435-447,

http://dx.doi.org/10.1080/09614524.2013.790940

\section{The authors}

Tobias Denskus (corresponding author) is a Senior Lecturer in Communication for Development at Malmö University in Sweden. His research on peace building, organisational ethnography and social media has been published in Third World Quarterly, Evaluation and Program Planning and Peace \& Change. He blogs at www.aidnography.de.

<tobias@aidnography.de>

Andrea S. Papan is a researcher at the Atlantic Centre of Excellence for Women's Health. She specialises in rights-based approaches to gender and development. She has worked in the UN system and consulted internationally on issues relating to gender and governance, gender and knowledge management, and gender and health. She is deeply interested in questions of transformative change. 